\title{
SEOM clinical guidelines for anaemia treatment in cancer patients (2020)
}

\author{
Y. Escobar Álvarez ${ }^{1}\left(\mathbb{D} \cdot\right.$ R. de las Peñas Bataller ${ }^{2}$ (D - J. Perez Altozano ${ }^{3} \cdot$ S. Ros Martínez ${ }^{4} \cdot$ A. Sabino Álvarez ${ }^{5}$.

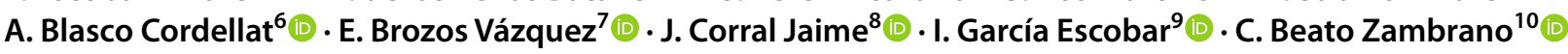

Accepted: 2 March 2021 / Published online: 25 March 2021

(c) The Author(s) 2021

\begin{abstract}
Anaemia is defined by the presence of haemoglobin $(\mathrm{Hb})$ levels $<13 \mathrm{~g} / \mathrm{dL}$ in men and $12 \mathrm{~g} / \mathrm{dL}$ in women. Up to $39 \%$ of cancer patients present it at the time of diagnosis and up to $40 \%$ have iron deficiency. Anaemia causes fatigue, functional deterioration and a reduction in the quality of life; it has also been associated with a poorer response to anti-tumour treatment and lower survival. Basic diagnostic tests for anaemia are simple and should be a routine part of clinical practice. These guidelines review the available evidence on the use of different therapies for treating anaemia: erythropoiesis-stimulating agents, iron supplements, and transfusion of blood products.
\end{abstract}

Keywords Anaemia $\cdot$ Erythropoiesis stimulating agents $\cdot$ Iron supplements $\cdot$ Transfusion of blood products

\section{Introduction}

Anaemia is defined by the presence of haemoglobin $(\mathrm{Hgb})$ levels $<13 \mathrm{~g} / \mathrm{dl}$ in men and $12 \mathrm{~g} / \mathrm{dl}$ in women. Iron deficiency (ID) is characterized by low transferrin saturation (TSI $<20 \%$ ) and can be absolute (depleted iron stores, serum

Y. Escobar Álvarez

yolandaesco@yahoo.es

R. de las Peñas Bataller

ramon.delaspenas@hospitalprovincial.es

J. Perez Altozano

jpaltozano@hotmail.com

S. Ros Martínez

silveriorosmartinez@gmail.com

A. Sabino Álvarez

arasabino@hotmail.com

A. Blasco Cordellat

blascocordellat@yahoo.es

E. Brozos Vázquez

elenambrozosv@hotmail.com

J. Corral Jaime

jesuscorraljaime@hotmail.com

I. García Escobar

naxto@ hotmail.com

C. Beato Zambrano

cbeatoz@hotmail.com ferritin $<30 \mathrm{ng} / \mathrm{ml}$ ) or functional (normal or increased serum ferritin); both are common complications in patients with solid tumours.

Up to $39 \%$ of cancer patients present anaemia at the time of diagnosis and up to $40 \%$ present ID; of these, about a third have $\mathrm{Hgb}$ levels $<12 \mathrm{~g} / \mathrm{dl}$. In addition, up to $53 \%$ of patients

1 Department of Medical Oncology, Hospital General Universitario Gregorio Marañón, Madrid, Spain

2 Department of Medical Oncology, Consorcio Hospitalario Provincial de Castellón, Castellón de la Plana, Spain

3 Department of Medical Oncology, Hospital Virgen de Los Lirios, Alcoy, Spain

4 Department of Medical Oncology, Hospital Universitario Virgen de la Arrixaca, Murcia, Spain

5 Department of Medical Oncology, Hospital Universitario Puerta del Mar, Cádiz, Spain

6 Department of Medical Oncology, Consorcio Hospital General Universitario, Valencia, Spain

7 Department of Medical Oncology, Hospitalario Clínico Universitario de Santiago, la Coruña, Spain

8 Department of Medical Oncology, Clínica Universidad de Navarra, Madrid, Spain

9 Present Address: Hospital General Universitario Virgen de las Nieves, Granada, Spain

10 Department of Medical Oncology, Hospital Universitario de Jerez de la Frontera, Cádiz, Spain 
who do not present anaemia at diagnosis will develop it during chemotherapy (CT) and/or radiotherapy (RT) treatment, so that up to $67 \%$ of cancer patients will present anaemia at some time during the evolution of their disease [1].

Anaemia causes fatigue, functional deterioration and reduced quality of life [2]. It has also been associated with a worse response to anti-tumour therapy and shorter survival.

The aetiology of cancer-related anaemia is multifactorial, and two or more factors can be present in the same patient. For example, anaemia may be caused by a combination of:

- A direct effect of the cancer (tumour bleeding, invasion of the bone marrow).

- Chemical factors produced by the tumour (auto-antibodies, inflammatory cytokines that affect erythropoietin production and block iron metabolism).

- An effect of cancer therapy (cell death induced by CT, RT, tyrosine kinase inhibitors (TKI) and monoclonal antibodies $(\mathrm{mAb})$.

Drug-induced anaemia is graded according to the CTCAE [3] (Table 1).

Cancer-related anaemia, therefore, is a multifactorial problem with immunologic, nutritional and metabolic components that affect its severity. For this reason, reversible causes must be identified and the different therapeutic options available for treatment must be used correctly (level of evidence I, recommendation grade A).

\section{Algorithm for the diagnosis of anaemia in cancer patients}

A correct diagnosis of anaemia requires a medical history that includes: personal history, status of the oncological disease (the type of primary tumour and stage of the disease, the different treatments received, chemotherapies with a high risk of haematological toxicity and their dates of administration are the most important data), clinical history and complete physical examination.

The most common symptoms presented by patients with anaemia are fatigue, dyspnoea on exertion, oedema in the lower limbs, cognitive impairment, confusion and depression. Clinical signs include pallor, tachycardia, and worsening of performance status (PS-ECOG) [5].

Blood tests required include a basic blood count, a ferrokinetic study (serum ferritin levels and transferrin saturation), biochemistry with creatinine (to assess kidney function), and C-reactive protein (marker of chronic inflammation) [5].

Since anaemia in cancer patients can be multifactorial, other complementary tests should be requested to determine the cause: occult blood in stool, urinary sediment, blood smear, coagulation tests, thyroid hormones and immunological studies [6]; bone marrow biopsy if tumour infiltration is suspected, an imaging test, such as computerized tomography and gastrointestinal endoscopy, to identify possible bleeding can also be useful. The algorithm shown in Fig. 1 can be used to diagnose anaemia in cancer patients.

It is important to differentiate between iron deficiency anaemia and chronic cancer-induced anaemia. Table 2 shows the parameters used to differentiate between these entities.

\section{Treatment of anaemia in cancer patients}

\section{Erythropoyetin-stimulating agents (ESA)}

The cloning of the human erythropoietin (EPO) gene in 1984 opened a new option of treatment for cancer-related anaemia. Numerous clinical trials have shown the efficacy and safety equivalence of different ESAs, which reduce transfusion needs in patients with chemotherapy-induced anaemia, achieve more sustained correction of anaemia, are associated with fewer risks than transfusions, and improve both blood flow and quality of life [7, 8].

However, the use of these agents has decreased considerably since 2005 following the publication of data that associated them with decreased survival.

Below, we analyse the indications and risks of the different ESAs available, as shown in Table 3.

Table 1 Anaemia grades according to the Common Terminology Criteria for Adverse Events (CTCAE) v 5.0 published on 27 November 2017

\begin{tabular}{|c|c|c|c|c|}
\hline Grade 1 & Grade 2 & Grade 3 & Grade 4 & Grade 5 \\
\hline \multirow[t]{2}{*}{$\begin{array}{c}(\mathrm{Hgb})<\mathrm{LLN}-10 \mathrm{~g} / \mathrm{dl} ;<\mathrm{LLN}- \\
6.2 \mathrm{mmol} / \mathrm{l},<\mathrm{LLN}-100 \mathrm{~g} / \mathrm{l}\end{array}$} & \multirow[t]{2}{*}{$\begin{array}{c}\mathrm{Hgb}<10.0-8.0 \mathrm{~g} / \mathrm{dl} ;<6.2- \\
\quad 4.9 \mathrm{mmol} / 1 ;<100-80 \mathrm{~g} / 1\end{array}$} & $\begin{array}{l}<8.0 \mathrm{~g} / \mathrm{dl} \\
<4.9 \mathrm{mmol} / 1 \\
<80 \mathrm{~g} / 1\end{array}$ & $\begin{array}{l}\text { Potentially life-threatening } \\
\text { consequences } \\
\text { Urgent intervention indi- } \\
\text { cated }\end{array}$ & \multirow[t]{2}{*}{ Death } \\
\hline & & Transfusion indicated & & \\
\hline
\end{tabular}

$L L N$ lower limit of normality 


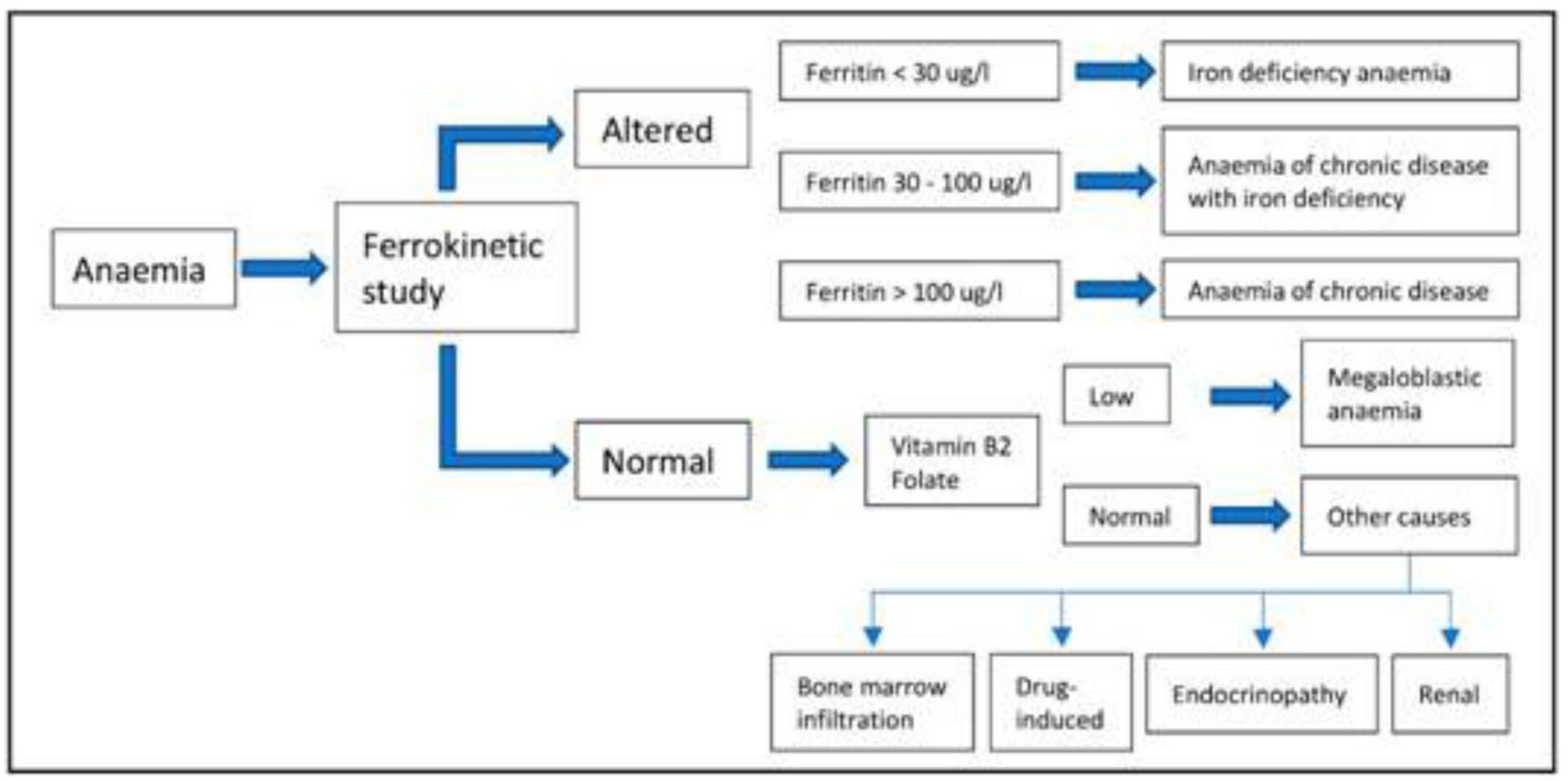

Fig. 1 Algorithm for the diagnosis of anaemia in cancer patients

\section{Indications for ESAs}

Table 2 Differences between iron deficiency anaemia and cancer-induced anaemia. (Adapted from Dr Muñoz Langa) [2]

\begin{tabular}{lll}
\hline & Iron deficiency anaemia & Cancer-induced anaemia \\
\hline Reticulocytes & High or low & Low \\
MCV/MCH* & Low or normal & Low or normal \\
Serum iron & Low & Low or normal \\
Serum ferritin & Low & Normal or high \\
Transferrin Saturation Index & Low or normal & Low \\
Total binding capacity & High & Low \\
Serum transferrin receptor & High & Normal \\
Bone marrow iron deposits & Absent & Present \\
\hline
\end{tabular}

* $M C H$ mean corpuscular haemoglobin, $M C V$ mean corpuscular volume
Leading agencies (EMA, FDA) and medical societies (ASCO/ASH, ESMO, NCCN) recommend the use of ESAs in $[9,10]$ :

- Patients with solid tumours and symptomatic anaemia under treatment with chemotherapy (level of evidence I, grade of recommendation A) or chemoradiotherapy (level of evidence II, grade of recommendation B).

- Patients with $\mathrm{Hgb}$ levels $<10 \mathrm{~g} / \mathrm{dl}$, or asymptomatic anaemia with $\mathrm{Hgb}$ levels $<8 \mathrm{~g} / \mathrm{dl}$ after correction of iron levels and other underlying causes (level of evidence I, grade of recommendation A).
- In patients with $\mathrm{Hgb}<7-8 \mathrm{~g} / \mathrm{dl}$ and/or symptomatic

anaemia, red blood cell transfusion should be considered before ESAs (level of evidence II, grade of recommendation B).

\section{Risks and complications}

Venous thromboembolism (VTE): In 2005, the results of some studies that linked the use of ESAs with an increase in mortality in cancer patients caused some alarm. Subsequent analyses found that this effect was limited to patients treated with $\mathrm{Hgb}$ levels $>12 \mathrm{~g} / \mathrm{dl}[11,12]$; therefore, prophylactic treatment in non-anaemic patients is not advised (level of evidence I, grade of recommendation A) due to the increased 


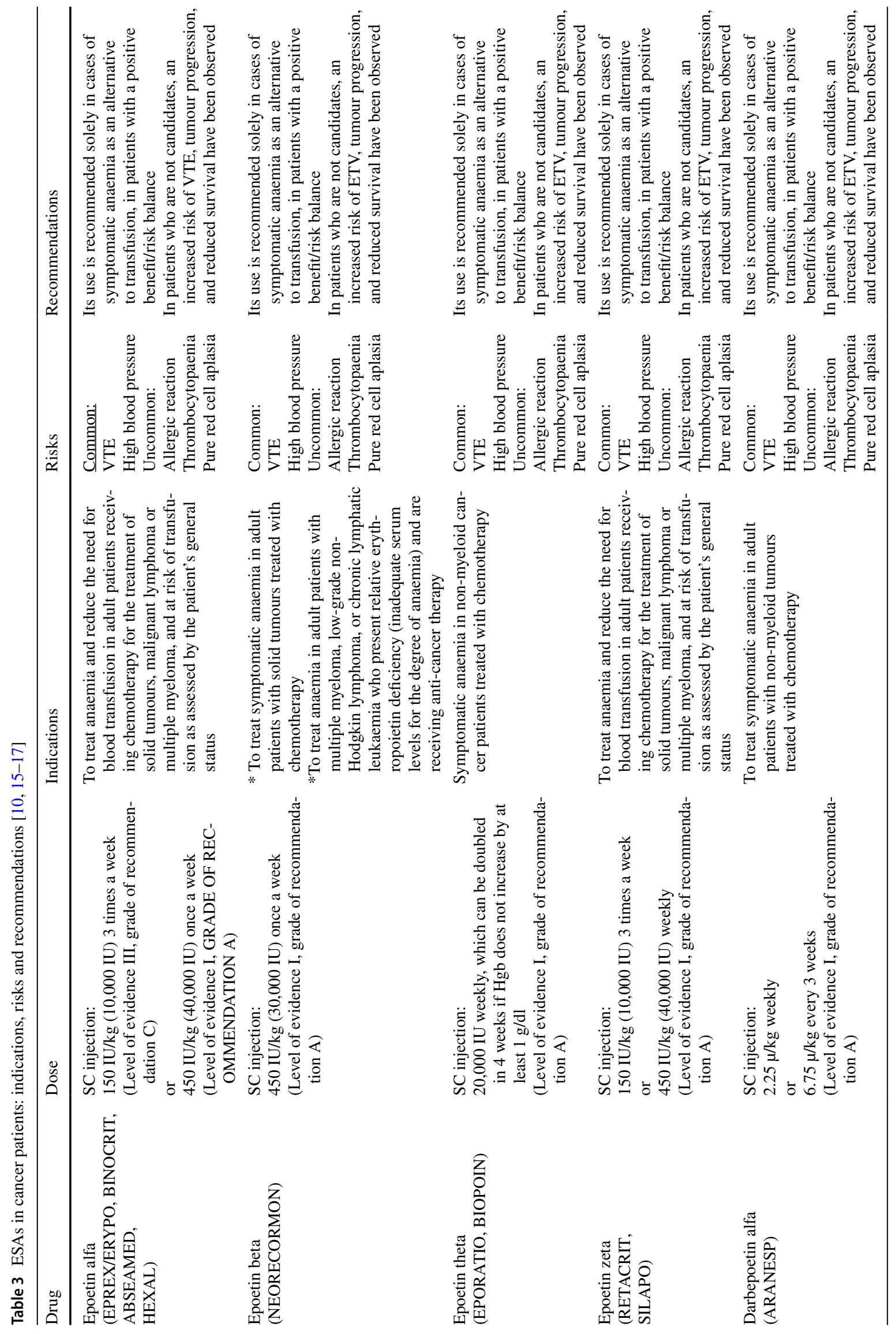


risk of thromboembolic complications. In these cases, other options should be considered, or the risks should be evaluated individually in elderly patients, patients on bed rest, with heart failure, thrombocytosis, a history of VTE, adenocarcinoma (particularly some subtypes, or pancreatic cancer) and with some cancer treatments. The use of antithrombotic prophylaxis or aspirin is not recommended in these cases $[12,13]$.

Other less common complications are [7]: Pure red cell aplasia (described in patients with chronic renal failure and caused by the appearance of anti-erythropoietin antibodies), arterial hypertension, thrombocytopaenia and allergic reactions.

\section{Controversy: survival and disease control}

The lower survival observed in cancer patients with anaemia appears to be associated with a poorer response to certain therapies when tissue hypoxia is present. Based on this finding, some authors have suggested that achieving $\mathrm{Hgb}>12 \mathrm{~g} /$ dl with ESAs will improve survival in patients receiving chemoradiotherapy $[11,14]$. Subsequent studies did not confirm this hypothesis, and suggested that this might be due to the appearance of thromboembolic phenomena in patients with $\mathrm{Hgb} 13-16 \mathrm{~g} / \mathrm{dl}$ due to the presence of erythropoietin receptors on the surface of tumour cells that would promote angiogenesis, tumour growth and therapeutic failure, and also to the activation of neovascularization by mechanisms independent of the erythropoietin receptor.

After analysing these studies, and on the assumption that ESAs are used in patients with symptomatic anaemia and $\mathrm{Hgb}<10 \mathrm{~g} / \mathrm{dl}$, various agencies and scientific societies have maintained their recommendation for use of ESAs, adding that they should be avoided in patients receiving therapy for curative intent and in patients with advanced tumours but long-term survival expectations, even if they develop anaemia secondary to treatment $[11,12]$. (Level of evidence IV, grade of recommendation C).

Table 3 shows the different ESAs available with their indications, risks and recommendations for use.

\section{Oral and intravenous iron supplementation}

The ECAS study found that more than $40 \%$ of patients included had iron deficiency (ID) and, of these, approximately one-third had Hgb levels $<12 \mathrm{~g} / \mathrm{dl}$; the same study indicated that the prevalence of ID in patients with solid tumours was higher than in haematological cancers and that, in these solid tumours, the prevalence of ID correlated with a more advanced tumour stage at the time of diagnosis, worse tumour response to treatment with chemotherapy and/or radiotherapy, and worse clinical status [18].

\section{Indications for iron supplementation}

Iron supplementation should be considered in patients undergoing chemotherapy who have anaemia with $\mathrm{Hgb} \leq 11 \mathrm{~g} / \mathrm{dl}$ or $\mathrm{Hgb}$ decrease $\geq 2 \mathrm{~g} / \mathrm{dl}$ from a baseline level $\leq 12 \mathrm{~g} / \mathrm{dl}[19]$.

It is important to note that ID can also be associated with impaired physical function, weakness and fatigue even in the absence of anaemia, so iron supplementation must also be considered in this circumstance [20].

The following situations are established based on three laboratory parameters to be determined before and during cancer therapy (serum iron-SI, transferrin saturation index - TSI, and ferritin) (level of evidence II and grade of recommendation A) [21]:

Possible functional iron deficiency (ferritin 500-800 ng/ $\mathrm{ml}$ and TSI $>50 \%$ ). In this case, treatment with an erythropoietin stimulating agent (ESA) or with iron supplements is not recommended; in certain selected patients, the use of intravenous (IV) iron may be considered to avoid the need for transfusion. All iron supplementation should be suspended when ferritin $>800 \mathrm{ng} / \mathrm{dl}$ and TSI $>50 \%$.

Functional iron deficiency (ferritin between 30-500 ng/ $\mathrm{ml}$, TSI $<50 \%$ and SI $<30 \mu / \mathrm{dl}$ ). This shows insufficient availability of iron despite adequate iron stores. Administration of IV iron together with ESAs is recommended (unless the latter are not indicated), as this improves the haematological response and reduces the number of transfusions. There is insufficient clinical evidence to indicate the routine use of IV iron in monotherapy without the concomitant use of ESAs.

Absolute iron deficiency (ferritin $<30 \mathrm{ng} / \mathrm{ml}$, TSI $<20 \%$ and $\mathrm{SI}<30 \mu / \mathrm{dl}$ ). Indicates that iron stores are depleted. Oral or intravenous iron supplements can be given. Oral iron should only be administered in the absence of inflammation; if no response is obtained after four weeks, switch to IV iron.

\section{Risks of iron supplementation}

Although long-term side effects have not been fully established, IV iron therapy does not increase the risk of infections, thromboembolic events, or cardiovascular disease; however, it should be avoided in patients with active infection or concomitant cytotoxic chemotherapy; specifically, IV iron should be given before or after chemotherapy or at the end of a treatment cycle (level of evidence III and grade of recommendation C) [19]. Like any other drug, iron can induce allergic reactions [22]. There is no clinical evidence linking IV iron therapy to cancer development or progression; in research models evaluating iron as a possible promoter of tumour growth, this effect has not been demonstrated $[2,3]$. 


\section{Iron supplement presentations}

Iron can be administered orally or intravenously. Although the oral form is suitable for most patients with iron deficiency anaemia, many with anaemia secondary to chemotherapy do not respond, may be intolerant, or may require higher doses than can be achieved with oral supplementation. In these cases, intravenous therapy is a better option [24]. Several studies in which iron supplementation was given in conjunction with ESAs suggest that intravenous iron is superior to oral iron in improving haemoglobin response rates $[25,26]$. No studies on iron supplementation in conjunction with ESAs provide evidence on how or when to repeat iron administration after the maximum initial dose has been administered.

The most common adverse events associated with intravenous iron are: hypotension, hypertension, nausea, vomiting, diarrhoea, pain, fever, dyspnoea, itching, headache, and dizziness [27].

The dosages of different intravenous iron supplements currently available are described in Table 4.

\section{Treatment of cancer-induced anaemia by transfusion of erythrocytary derivatives}

Data on red blood cell (RBC) transfusions in cancer patients come mainly from studies in surgical patients. Studies performed in large population groups and meta-analyses suggest an independent association between RBC transfusion and an increased risk of mortality, morbidity and cancer recurrence [28-31]. However, there are few randomized studies in patients undergoing chemotherapy $[32,33]$.

Standard RBCs are obtained by fractionating whole blood. Currently, nearly all blood is fractionated by centrifugation into its main components: red blood cells, plasma and platelets. RBCs are stored suspended in a conservation medium containing an anticoagulant (citrate) together with glucose, adenine and phosphate, intended to maintain ATP levels by means of glycolytic metabolism. RBCs are stored at $4^{\circ} \pm 2^{\circ} \mathrm{C}$ to reduce their metabolic requirements and thus prolong conservation and delay bacterial growth in the rare event of the bag being accidentally contaminated by bacteria.

RBC transfusion in cancer patients is indicated above all in patients with severe anaemia and symptoms that require rapid recovery of haemoglobin and haematocrit levels. Elevation of these parameters and the corresponding symptomatic improvement will be transitory; therefore, the aetiology of anaemia should always be investigated.

In patients with no cardiovascular risk factors, transfusion is indicated if $\mathrm{Hgb}<7-8 \mathrm{~g} / \mathrm{dl}$ (Htc: $21-24 \%$ ) [34-36] and very rarely if $\mathrm{Hgb}>9-10 \mathrm{~g} / \mathrm{dl}$ (Htc: $27-30 \%)$. Unless justified, Hgb levels should not be allowed to remain below $7-8 \mathrm{~g} / \mathrm{d}$ for any length of time. In patients with cardiovascular risk factors, particularly coronary heart disease, the minimum Hgb threshold should be higher, around $9 \mathrm{~g} / \mathrm{d}$ [37]; patients with symptomatic anaemia should be transfused, regardless of these $\mathrm{Hgb}$ thresholds.

The correct RBC dose is calculated considering that 1 unit RBC increases $\mathrm{Hgb}$ from 1 to $1.5 \mathrm{~g} / \mathrm{l}$ and haematocrit from 2 to $3 \%$; therefore, dosage must be titrated individually, considering the characteristics of the patient and the minimum volume needed to correct the symptoms.

Immunosuppressed patients, due to the risk of post-transfusion graft-versus-host disease (GVHD), should receive irradiated blood components. Washed RBCs are indicated in patients with a history of severe post-transfusion allergic or anaphylactic reactions.

The main drawbacks of blood transfusion include the increased risk of thrombotic events and transfusion-related adverse effects. These include immediate reactions (during transfusion or over the following $24 \mathrm{~h}$ ), such as acute

Table 4 Iron compounds and approved dosages in patients with solid tumours and haematologic malignancies

\begin{tabular}{|c|c|c|c|}
\hline Compound & Iron sucrose & Low molecular weight dextran iron & Ferric carboxymaltose iron \\
\hline Test dose & $\begin{array}{l}\text { Medical judgement, } \\
\text { depending on the } \\
\text { risk of reaction }\end{array}$ & Slow infusion of $25 \mathrm{mg}$ over $15 \mathrm{~min}$ & Medical judgement, depending on the risk of reaction \\
\hline Dosage & $\begin{array}{l}200 \mathrm{mg} \text { IV over } \\
30-60 \text { min (every } \\
2-3 \text { weeks) or } \\
200 \mathrm{mg} \text { IV over } \\
2-5 \text { min, } 5 \text { times in } \\
14 \text { days } \\
\text { Individual doses } \\
>300 \mathrm{mg} \text { not rec- } \\
\text { ommended } \\
\text { Total } \\
\text { dose }=1000 \mathrm{mg}\end{array}$ & $\begin{array}{l}100-200 \mathrm{mg} \text { IV over } 30 \mathrm{~min} \\
\text { Repeat dosing once a week for } 10 \text { doses for a total } \\
\text { of } 1000 \mathrm{mg} \text { or } \\
\text { Full dose infusion over } 4-6 \mathrm{~h} \text { (total dose calcu- } \\
\text { lated in } 500 \mathrm{ml} 0.9 \% \mathrm{NaCl} \text { solution at } 175 \mathrm{ml} / \mathrm{h} \text { ) }\end{array}$ & $\begin{array}{l}750 \mathrm{mg} \text { IV in patients } \geq 50 \mathrm{~kg} \text { and repeat dose at least } \\
\text { once } 7 \text { days later or } \\
15-20 \mathrm{mg} / \mathrm{kg} \text { IV in patients }<50 \mathrm{~kg} \text { and repeat dose } \\
\text { at least once } 7 \text { days later } \\
\text { Minimum infusion time: } 15 \mathrm{~min} \\
\text { Total dose }=1500 \mathrm{mg}\end{array}$ \\
\hline
\end{tabular}


haemolytic reaction, allergic reactions, transfusion-related acute lung injury (TRALY), volume overload, non-immune haemolytic anaemia, hypotensive reactions, and fever; and delayed reactions, such as delayed haemolytic transfusion reaction, transfusion-related graft-versus-host disease, transmission of infectious diseases, transfusion hemosiderosis, and particularly common in cancer patients, allergic reactions and volume overload.

\section{Conclusion}

According to the above information, the following recommendations are established for anaemia treatment in cancer patients:

\section{Recommendations for ESA administration}

\section{Indications}

Patients with solid tumours and symptomatic anaemia under treatment with chemotherapy (level of evidence I, grade of recommendation A) or chemoradiotherapy (level of evidence II, grade of recommendation B) who present Hgb levels $<10 \mathrm{~g} /$ dl or asymptomatic anaemia with Hgb levels $<8 \mathrm{~g} / \mathrm{dl}$, after correction of iron levels or other underlying causes (level of evidence I, grade of recommendation A).

ESAs should not be used in patients who are not receiving chemotherapy (level of evidence I, grade of recommendation A).

\section{Duration and dosage}

Administer until stable Hgb values that avoid or reduce the need for red blood cell transfusion have been achieved, without exceeding $12 \mathrm{~g} / \mathrm{dl}$ (level of evidence IV, grade of recommendation B).

Increasing the dose or switching drugs after 6-8 weeks of treatment in non-responders is not recommended, except in the case of epoetin theta; instead, treatment should be suspended (level of evidence II, grade of recommendation B).

\section{Toxicity and contraindications}

The risk of thromboembolic events must be carefully evaluated and the patient duly informed. ESAs should not be used in patients with poorly controlled hypertension. (Level of evidence I, grade of recommendation A).

\section{Recommendations for iron supplementation}

\section{Indications}

Iron supplementation should be considered in patients undergoing chemotherapy who have anaemia with $\mathrm{Hgb} \leq 11 \mathrm{~g} / \mathrm{dl}$ or $\mathrm{Hgb}$ decrease $\geq 2 \mathrm{~g} / \mathrm{dl}$ from a baseline level $\leq 12 \mathrm{~g} / \mathrm{dl}$.

IV iron + ESA is recommended to treat functional iron deficiency (ferritin 30-500 ng/ml, TSI $<50 \%$, serum $\mathrm{Fe}<30$ $\mu / \mathrm{dl}$ ) (level of evidence II, grade of recommendation A).

Oral or intravenous iron is recommended to treat absolute iron deficiency (ferritin $<30 \mathrm{ng} / \mathrm{ml}$, TSI $<20 \%$, serum $\mathrm{Fe}<30 \mu / \mathrm{dl}$ ). If no response is obtained with oral treatment after four weeks, switch to IV iron. (Level of evidence II, grade of recommendation A).

Neither ESA nor iron supplementation is recommended to treat possible functional iron deficiency (ferritin 500-800 ng/ $\mathrm{ml}$ and TSI $>50 \%$ ) All iron supplementation should be suspended when ferritin $>800 \mathrm{ng} / \mathrm{dl}$ and TSI $>50 \%$. (Level of evidence II, grade of recommendation A).

\section{Toxicity and contraindications}

Iron does not increase the risk of infections, thromboembolic events, or cardiovascular morbidity; IV iron should be administered before or after chemotherapy or at the end of a treatment cycle (level of evidence III, grade of recommendation C). There is no clinical evidence linking IV iron therapy to cancer development or progression.

\section{Recommendations for blood transfusion}

Consider red blood cell transfusion in patients with $\mathrm{Hb}<7-8 \mathrm{~g} / \mathrm{dl}$ (and $<9 \mathrm{~g} / \mathrm{dl}$ if cardiovascular risk factors are present) and/or severe symptoms of anaemia that need rapid correction of $\mathrm{Hgb}$ or symptoms (level of evidence II, grade of recommendation $\mathrm{B}$ ).

\section{Declarations}

Conflict of interest YE, RdP, JPA, SR, AS, AB, EB, JC, IGE have nothing to disclose. CB reports education Grants from Leo Pharma and Vifor.

Ethical approval The current study has been performed in accordance with the ethical standards laid down in the 1964 Declaration of Helsinki and its later amendments.

Informed consent For this type of study formal consent is not required.

Open Access This article is licensed under a Creative Commons Attribution 4.0 International License, which permits use, sharing, adaptation, distribution and reproduction in any medium or format, as long as you give appropriate credit to the original author(s) and the source, 
provide a link to the Creative Commons licence, and indicate if changes were made. The images or other third party material in this article are included in the article's Creative Commons licence, unless indicated otherwise in a credit line to the material. If material is not included in the article's Creative Commons licence and your intended use is not permitted by statutory regulation or exceeds the permitted use, you will need to obtain permission directly from the copyright holder. To view a copy of this licence, visit http://creativecommons.org/licenses/by/4.0/.

\section{References}

1. Ludwig H, Van Belle S, Barrett-Lee P, Birgegard G, Bokemeyer C, Gascon P, et al. The European Cancer Anaemia Survey (ECAS): a large, multinational, prospective survey defining the prevalence, incidence, and treatment of anaemia in cancer patients. Eur J Cancer. 2004;40(15):2293-306.

2. Cella D, Kallich J, McDermott A, Xu X. The longitudinal relationship of hemoglobin, fatigue and quality of life in anemic cancer patients: results from five randomized clinical trials. Ann Oncol. 2004;15:979-86.

3. https://ctep.cancer.gov/protocoldevelopment/electronic_applicatio ns/docs/CTCAE_v5_Quick_Reference_8.5x11.pdf (Accessed on March 09, 2018).

4. NCCN Cancer and chemotherapy-induced anemia, versión 2.2019.

5. Manejo de la anemia y déficit de hierro en pacientes oncológicos. José Muñoz Langa.

6. Management of cancer-associated anemia with erythropoiesisstimulating agents: ASCO/ASH Clinical Practice Guideline Update (Bohlius) J Clin Oncol 37:1336-1351

7. Tonia T, Mettler A, Robert N, et al. Erythropoietin or darbepoetin for patients with cancer. Cochrane Database Syst Rev. 2012;12:CD003407. https://doi.org/10.1002/14651858.CD003 407.pub5.

8. Bohlius J, Tonia T, Nüesch E, et al. Effects of erythropoiesisstimulating agents on fatigue and anaemia related symptoms in cancer patients: systematic review and meta-analyses of published and unpublished data. Br J Cancer. 2014;111:33-45.

9. Bohlius J, Bohlke K, Castelli R, et al. Management of cancerassociated anemia with erythropoiesis-stimulating agents: ASCO/ASH Clinical Practice Guideline Update. J Clin Oncol. 2019;37(15):1336-51.

10. Aapro M, Beguin Y, Nüesch E, et al. Management of Anaemia and Iron Deficiency in Patients With Cancer: ESMO Clinical Practice Guidelines. Ann Oncol. 2018; 29 (4): iv96-iv110.

11. Leyland-jones B, Semiglazov V, Pawlicki M, et al. Maintaining normal hemoglobin le- vels with epoetin alfa in mainly nonanemi patients with metastatic breast cancer re- ceiving first-line chemotherapy: asurvival study. J Clin Oncol. 2005;23:5960-72.

12. Glaspy J, Crawford J, Vansteenkiste J, et al. Erythropoiesis-stimulating agents in oncology: a study-level meta-analysis of survival and other safety outcomes. Br J Cancer. 2010;102:301-15.

13. Muñoz Martín AJ, Gallardo Díaz E, García Escobar I, et al. SEOM clinical guideline of venous thromboembolism (VTE) and cancer (2019). Clin Transl Oncol. 2020;22(2):171-86.

14. Henke M, Laszig R, Rübe C, et al. Erythropoietin to treat head and neck cancer patients with anemia undergoing radiotherapy: a randomized, double-blind, placebo-controlled trial. Lancet. 2003;362:1255.

15. Cabrera García L, Ruíz Antorán B, Sancho LA. Eritropoyetina: revisión de sus indicaciones. Inf Ter Nac Salud. 2009;33:3-9.

16. Consenso sobre el uso de agentes eritropoyéticos en pacientes anémicos con cáncer. Esquemas de administración. César-Augusto Rodríguez Sánchez. Prodrug Multimedia 2007, SL. ISBN: 978-84-95972-43-9.
17. Eprex, Binocrit, Abseamed, Hexal, Neorecormon, Eporatio, Biopoin, Retacrit, Silapo, Aranesp. Ficha técnica del medicamento. The European Agency for the Evaluation of Medicinal Products (EMEA). Committee for Propietary Medicinal Products (CPMP). European Public Assessment Report (EPAR): Binocrit (2009), Abseamed (2009), Hexal (2009), Neorecormon (2004), Eporatio (2009), Biopoin (2009), Retacrit (2008), Silapo (2007), Aranesp (2004). Disponibles en: http://www.emea.europa.es/.

18. Ludwig H, Van Belle S, Barrett-Lee $\mathrm{P}$, Birgegård G, Bokemeyer C, Gascón P, et al. The European Cancer Anaemia Survey (ECAS): a large, multinational, prospective survey defining the prevalence, incidence, and treatment of anaemia in cancer patients. Eur J Cancer. 2004;40(15):2293-306.

19. Aapro M, Beguin C, Bokemeyer M, et al. Management of anemia and iron deficiency in patients with cancer: ESMO Clinical Practice Guidelines. Ann Oncol. 2018;29(4):96-101.

20. De Castro J, Gascón P, Casas A, Muñoz-Langa J, Alberola V, Cucala M, et al. Iron deficiency in patients with solid tumours: prevalence and management in clinical practice. Clin Transl Oncol. 2014;16(9):823-8.

21. Sue Becker P, Griffiths EA, Alwan L, et al. Cancer and Chemotherapy-Induced Anemia. In Hematopoietic Growth Factors NCCN Clinical Practice Guidelines in Oncology (NCCN Guidelines ()$)$ v2.2020.

22. European Medicines Agency. New recommendations to manage risk of allergic reactions with intravenous iron-containing medicines 2013; http://www.ema.europa.eu/docs/en_GB/document_ library/Press_release/2013/06/WC500144874.pdf.

23. Rezazadeh H, Nayebi AR, Garjani A, et al. Evidence that iron overload plus croton oil induce skin tumours in mice. Hum Exp Toxicol. 2005;24:409-13.

24. Silverstein SB, Gilreath JA, Rodgers GM. Intravenous iron therapy: a summary of treatment options and review of guidelines. J Pharm Pract. 2008;21:431-43.

25. Auerbach M, Ballard H, Trout JR, et al. Intravenous iron optimizes the response to recombinant human erythropoietin in cancer patients with chemotherapy-related anemia: a multicenter, openlabel, randomized trial. J Clin Oncol. 2004;22:1301-7.

26. Bastit L, Vandebroek A, Altintas S, et al. Randomized, multicenter, controlled trial comparing the efficacy and safety of darbepoetin alpha administered every 3 weeks with or without intravenous iron in patients with chemotherapy-induced anemia. J Clin Oncol. 2008;26:1611-8.

27. Silverstein SB, Rodgers GM. Parenteral iron therapy options. Am J Hematol. 2004;76:74-8.

28. Al-Refaie WB, Parsons HM, Markin A, et al. Blood transfusion and cancer surgery outcomes: a continued reason for concern. Surgery. 2012;152(344-354):114.

29. Amato A, Pescatori M. Perioperative blood transfusions for the recurrence of colorectal cancer. Cochrane Database Syst Rev. 2006;1(CD005033):115.

30. Bakkum-Gamez JN, Dowdy SC, Borah BJ, et al. Predictors and costs of surgical site infections in patients with endometrial cancer. Gynecol Oncol. 2013;130(100-106):116.

31. Halabi WJ, Jafari MD, Nguyen VQ, et al. Blood transfusions in colorectal cancer surgery: incidence, outcomes, and predictive factors: an American College of Surgeons National Surgical Quality Improvement Program analysis. Am J Surg. 2013;206:1024-1032.1.

32. Link H, Schmitz S. Treatment of cancer-associated anaemia: results from a two-day cross-sectional survey in Germany. Onkologie. 2013;36(266-272):106.

33. Ludwig H, Aapro M, Bokemeyer C, et al. A European patient record study on diagnosis and treatment of chemotherapy-induced anaemia. Support Care Cancer. 2014;22:2197-206. 
34. National Comprehensive Cancer Network. NCCN Practice Guidelines in Oncology; Cancer and Chemotherapy-Induced Anemiav.1.2018, 2017; http://www.nccn.org/professionals/physician_gls/ PDF/anemia.

35. Rizzo JD, Brouwers M, Hurley P, et al. American Society of Hematology/American Society of Clinical Oncology clinical practice guideline update on the use of epoetin and darbepoetin in adult patients with cancer. Blood. 2010;116:4045-59.

36. Callum JL, Waters JH, Shaz BH, et al. The AABB recommendations for the choosing wisely campaign of the American Board of Internal Medicine. Transfusion. 2014;54(2344-2352):123.
37. Carson JL, Grossman BJ, Kleinman S, et al. Red blood cell transfusion: a clinical practice guideline from the AABB. Ann Intern Med. 2012;157:49-58.

Publisher's Note Springer Nature remains neutral with regard to jurisdictional claims in published maps and institutional affiliations. 